\title{
A risk management audit: are we complying with the national guidelines for sedation by non-anaesthetists?
}

\author{
Mark F Nicol
}

\section{Accident and \\ Emergency \\ Department, Royal \\ Devon and Exeter \\ Hospital (Wonford), \\ Barrack Road, Exeter \\ EX2 5DW}

Correspondence to:

Dr Nicol.

Accepted 13 November 1998

\begin{abstract}
Objectives-To assess the effect of a preprinted form in ensuring an improved and sustained quality of documentation of clinical data in compliance with the national guidelines for sedation by nonanaesthetists.

Design-The process of retrospective case note audit was used to identify areas of poor performance, reiterate national guidelines, introduce a post-sedation advice sheet, and demonstrate improvement.
\end{abstract}

Setting-Emergency Department, Musgrove Park Hospital, Taunton.

Subjects-Forty seven patients requiring sedation for relocation of a dislocated

\section{MONITORING CHART FOR PROCEDURES PERFORMED UNDER SEDATION}

NB. Sedation is a drug induced reduction in conscious level of a patient who remains able to respond to command

Date:

Doctor(s) present:

Patient details label

Doctor performing procedure:

Nurse present:

\begin{tabular}{|l|l|}
\hline Anaesthetic & \\
\hline Allergy & \\
\hline Medication & \\
\hline Past medical/surgical history & \\
\hline Last meal (time) & \\
\hline
\end{tabular}

\begin{tabular}{|l|l|l|l|l|}
\hline Drugs given & Dose (mg) & Route (IV/inhaled) & Time & Given by \\
\hline (sedative) & & & & \\
\hline (analgesic) & & & & \\
\hline (other) & & & & \\
\hline
\end{tabular}

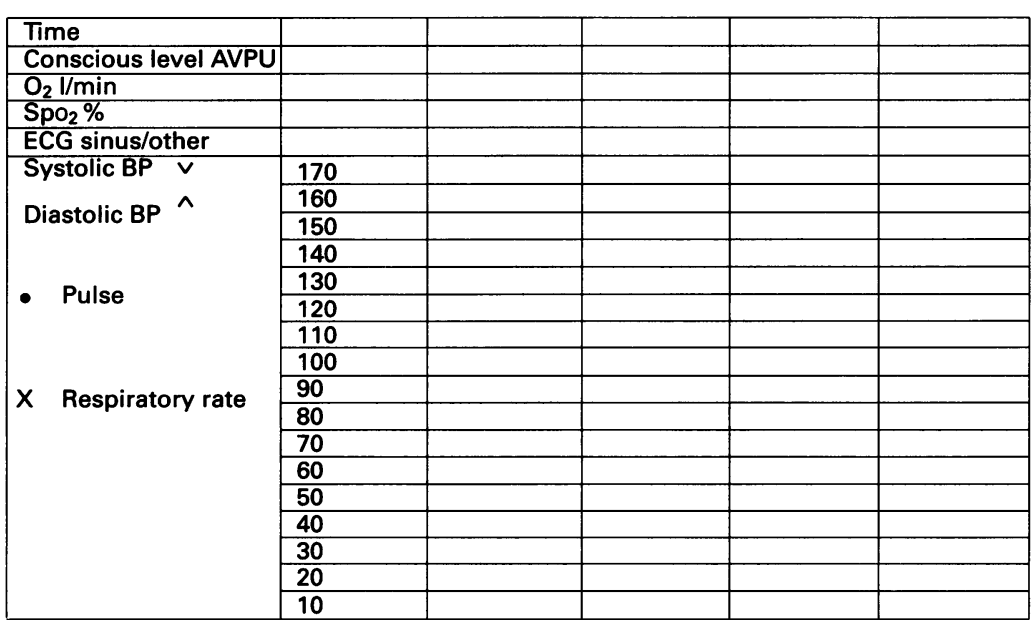

The procedure was: uneventful/problematic

(delete as appropriate)

Figure 1 Monitoring chart for procedures performed under sedation. AVPU = A, alert; $V$, responds to verbal stimulus; $P$, responds to painful stimulus; $U$, unresponsive; $B P=b l o o d$ pressure; $E C G=$ electrocardiography; IV = intravenous; $\mathrm{O}_{2}=$ oxygen; $S \mathrm{PO}_{2}=$ pulse oximetry saturation. shoulder or manipulation of a Colles' fracture between July and October 1996 and July and October 1997.

Main outcome measures-Evidence that the following items had been documented: consent for procedure, risk assessment, monitored observations, prophylactic use of supplementary oxygen, and discharging patients with printed advice.

Case note review was performed before $(n=23)$ and after $(n=24)$ the introduction of a sedation audit form. Notes were analysed for the above outcome measures. The monitored observations analysed included: pulse oximetry, respiratory rate, pulse rate, blood pressure, electrocardiography, and conscious level.

Results-Use of the form significantly improved documentation of most parameters measured.

Conclusions-Introduction of the form, together with staff education, resulted in enhanced documentation of data and improved conformity with national guidelines. A risk management approach to pre-empting critical incidents following sedation, can be adopted in this area of emergency medicine.

(F Accid Emerg Med 1999;16:120-122)

Keywords: sedation; risk management; preprinted form

This study aimed to demonstrate that the process of audit and an audit tool - a formcan be used to aid risk management and, at the same time, improve compliance with National Guidelines for sedation by non-anaesthetists. ${ }^{1}$

Despite several studies highlighting inadequate monitoring and assessment of patients undergoing sedation in the emergency department, ${ }^{2-5}$ this is the first study auditing compliance with these guidelines and audit the dispensing of post-procedure written advice. Kendall et al reported two deaths in association with patients being sedated in the emergency department. $^{2}$

\section{Methods}

Audit is crucial in evaluating compliance with guidelines, although guidelines are redundant if the principles are ignored. ${ }^{6}$ Before the audit a computer search highlighted 23 consecutive patients in a three month period in 1996 who had undergone sedation for a procedure in the emergency department. The emergency department cards were then analysed for documented evidence of: consent for procedure; 
Table 1 Discharge advice sheet - patients who underwent procedure under sedation

You have received a sedative drug which may impair your judgment over the next 24 hours, the doctor advises the following:

- DO phone 01823342906 if you are worried

- DO NOT drink alcohol

- DO rest

- DO NOT drive a vehicle

- DO NOT operate machinery

- DO NOT sign any legally binding documents

BE SAFE

BE WISE

FOLLOW ADVICE

Note: It is an offence (section 4 Road Traffic Act 1988) to drive when unfit to do so because of drugs, and will probably invalidate your insurance policy

risk assessment; results of monitored observations; prophylactic use of supplementary oxygen; and dispensing of the printed postsedation advice sheet at discharge.

Risk assessment was regarded as being taken if a past medical history was recorded or if "previous fit and well" was written. Similarly, supplementary oxygen was regarded as being taken if oxygen or a mixture of nitrous oxygen and oxygen (Entonox) was recorded.

\section{STANDARDS}

The principles of the Royal College of Surgeons working party report on guidelines for sedation by non-anaesthetists served as a standard.

\section{INTERVENTION}

The standards were incorporated onto an A4 sized form (fig 1) and introduced after staff education. The timing of the period after the form was introduced was selected when the medical staff would have been of similar experience to those in the period before the form was used. The case notes of 24 consecutive patients requiring sedation in the period after the form was introduced were then audited. The form contained prompts for demographic details, allergies, current medication, past medical history, and times of last meal. A chart for documenting observations included AVPU rather than the Glasgow coma score for the assessment of conscious level (A, alert; V, responds to verbal stimulus; $P$, responds to painful stimulus; $U$, unresponsive).The advice sheet to be given after sedation (table 1) was recommended during staff education and was introduced at the same time.

STATISTICAL ANALYSIS

Each set of outcome measures was analysed for association using Yates's corrected square test of independence. The $p$ value ( $5 \%$ level of significance) for each test of independence is presented in column 3 of table 2 . In addition, the relative risk ( $R R$, or relative probability) was calculated for each set of outcome measures and these are given in column 4 . The calculation returns the relative probability of obtaining documented evidence before compared with after the introduction of the form. This can be expressed as the relative probability of obtaining documented evidence AFTER the form was introduced divided by the relative probability of obtaining it BEFORE.

$R R>1$ was considered statistically significant and $95 \%$ confidence intervals were calculated for each $R R$. This represents the range within which the true value for the $R R$ is expected to lie with $95 \%$ degree of certainty.

\section{Results}

The results are shown in fig 2 and table 2.

During the preaudit period 23 patients received intravenous sedation for the reduction of shoulder dislocations or Colles' fracture and 24 patients in the period after the introduction after the form. The results are not stratified by condition, operator, or choice of drugs. Of the four patients who did not have drug name/dose documented, two had the drug name documented without the dose. In two cases neither the drug name nor the dose was recorded. All four accident and emergency cards had "IV sedation" written or coded on them. In the preaudit group 10 patients had an isolated pulse and blood pressure (BP) recorded in the triage area of the card. There was no clear evidence of BP monitoring neither through nor after the procedure in any of the preaudit group. ${ }^{7}$ Electrocardiography (ECG) monitoring was indicated for only 12 in the preaudit group and 10 in the audit group (these patients being either over 60 years old or having a

Table 2 Documentation of parameters before and after the introduction of the preprinted form

\begin{tabular}{|c|c|c|c|c|}
\hline & Before & After & $\begin{array}{l}\text { p Value } 5 \% \\
\text { level }\end{array}$ & $\begin{array}{l}\text { RR: relative probability of obtaining } \\
\text { completed documentation ( } 95 \% \\
\text { confidence intervals) }\end{array}$ \\
\hline Consent & $14 / 23$ & $21 / 24$ & 0.079 & $1.44(1<\mathrm{RR}<2.06)$ \\
\hline Form used & $\mathbf{n} / \mathbf{a}$ & $14 / 24$ & & $\mathbf{n} / \mathbf{a}$ \\
\hline Drug name/dose & $19 / 23$ & $24 / 24$ & 0.106 & $1.21(1<R R<1.46)$ \\
\hline Risk assessment & $6 / 23$ & $19 / 24$ & 0.0008 & $3.03(1.48<R R<6.22)$ \\
\hline Supplementary oxygen & $0 / 23$ & $11 / 24$ & 0.0008 & $R R$ not returned \\
\hline Pulse oximetry saturation & $2 / 23$ & $17 / 24$ & 0.00005 & $8.15(2.11<R R<31.39)$ \\
\hline Respiratory rate & $1 / 23$ & $3 / 24$ & 0.632 & $2.88(0.32<R R<25.68)$ \\
\hline $\mathrm{BP}$ and pulse (before, during, and after procedure) & $0 / 23$ & $20 / 24$ & $<0.0001$ & RR not returned \\
\hline ECG, single lead & $1 / 12$ & $5 / 10$ & 0.083 & $6(0.83<R R<43.29)$ \\
\hline Conscious level & $2 / 23$ & $9 / 24$ & 0.047 & $4.31(1.04<R R<17.87)$ \\
\hline Advice after sedation & $\mathbf{n} / \mathbf{a}$ & $7 / 18$ & & \\
\hline Overall relative probability of completed documentation & & & & $2.67(2.03<R R<3.53)$ \\
\hline
\end{tabular}

$\mathrm{BP}=$ blood pressure; $\mathrm{ECG}=$ electrocardiography. 


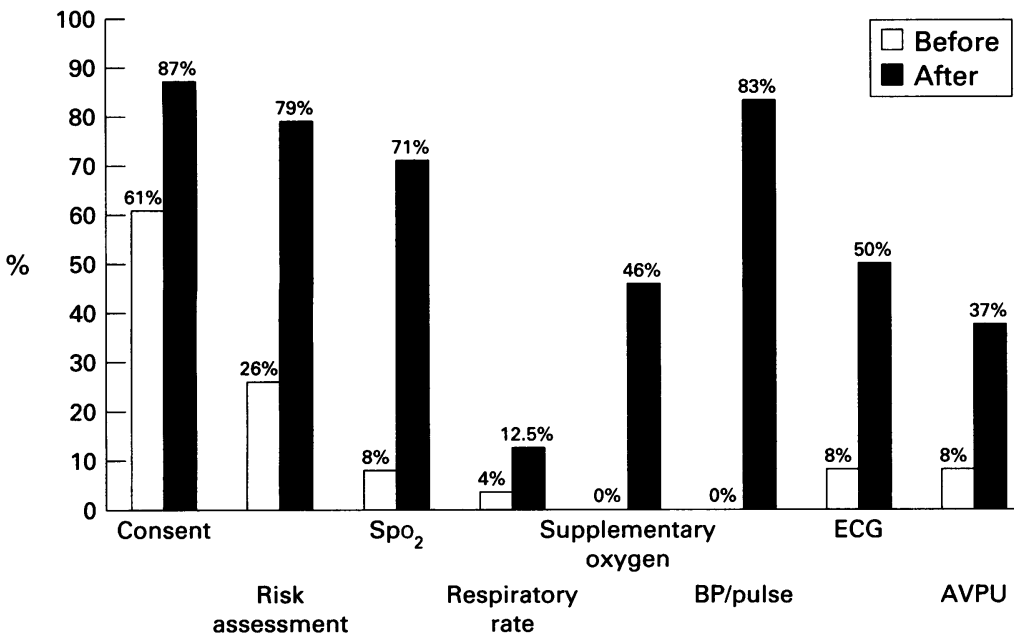

Figure 2 Documentation of parameters before and after the introduction of the preprinted form. $A V P U=A$, alert; $V$, responds to verbal stimulus; $P$, responds to painful stimulus; $U$, unresponsive; $B P=$ blood pressure $E C G=$ electrocardiography; $\mathrm{SpO}_{2}=$ pulse oximetry saturation. emergency medicine as a reaction to problems encountered in clinical practice. ${ }^{10}$ The use of this form, however, is to pre-empt a problem. Morbidity and mortality complicate sedation outside the emergency department. ${ }^{11}$ Critical events also complicate sedation within the emergency department. ${ }^{23}$ Respondents to the survey of Aslam and Woods indicated that in $10 \%$ of emergency departments no routine monitoring took place, $52 \%$ did not monitor ECG, $35 \%$ did not monitor pulse oximeter saturations, and $33 \%$ did not monitor blood pressure. ${ }^{5}$ These and other results would suggest that these risks are not being managed and critical incidents are not being pre-empted. ${ }^{4}$

This audit indicates that improved practice in several areas of weakness can be demonstrated, even with small numbers of patients, through introduction of an inexpensive development. This form, recognisable as an observation chart, may serve as a prompt to good practice and be used as a tool for reaudit particularly when new staff enter the department. It is simple, patient specific, and user friendly ${ }^{12}$ and may be incorporated into every emergency department's guideline on sedation.

Litigation has been successful as a result of a failure to adhere to professional guidelines, despite the fact that the defendant could have escaped liability on the basis of the Bolam test. $^{13}$

This audit regards the application of these guidelines as best practice and should be considered by all documenting procedures performed under sedation thus removing the need to rely, uncertainly, on the Bolam test as a last resort.

Thanks to Ms Fiona Parkin, Research and Development Support Unit, Musgrove Park Hospital, Taunton and Mr S E McCabe, Royal Gloucester Hospital. Thanks also to D J C Nicol. results in these respects.

Small numbers of patients were included in the study, however the difference in the results is still significant. It is interesting to note that improved documentation of consent, observations, and the discharge sheet is to be noted in the 10 patients for whom the audit form itself had not been used. Significantly improved documentation occurred for most areas: BP, supplementary oxygen, and conscious level.

Overall, completed documentation of parameters was three times more likely in the audit group compared with the preaudit group. As such, the results may be regarded as predictable.

However, documentation of respiratory rate was not improved by the introduction of the form. This suggests a lack of understanding of the limitations of pulse oximetry. The small improvement in the use of ECG would also suggest it is undervalued. This lack of improvement in individual parameters was not predicted. We propose to educate the staff further on these issues in a course on sedation for nonanaesthetists. The department at present does not have capnometry for non-intubated spontaneously ventilating patients. ${ }^{9}$

Preprinted forms have been associated with improved documentation in other areas of
1 Royal College of Surgeons. Report of the working party on guidelines for sedation by non-anaesthetists. London: Royal Guidelines for sedation by non-anast

2 Kendall JM, Allen PE, McCabe SE. A tide of change in the management of an old fracture. $\mathcal{f}$ Accid Emerg Med management of

3 Ilkhanipour K, Juels CR, Langdorf MI. Paediatric pain control and conscious sedation: a survey of emergency medicine residencies [see comments]. Acad Emerg Med 1994;1:368-72.

4 Hewitt S, Hartley R. Intravenous sedation in accident and emergency departments: a nationwide survey. Ann $R$ Coll Surg Engl 1994;76:213.

5 Aslam BH, Woods I. Intravenous sedation in accident and emergency departments: a nationwide survey. Ann R Coll Surg Engl 1994;76:19-21.

6 NHS Executive. Clinical guidelines: using clinical guidelines to improve patient care within the NHS. London: NHS Executive, May 1996 Recommendations for standards of monitoring during anaesthe-

8 Inglis A, Daniel M. A survey of information supplied to day-case patients. Health Bull (Edinb) 1995;53:91-3.

9 Santos LJ, Varon J, Pic-Alaus L, et al. Practical uses of endSantos LJ, Varon J, Pic-Alaus $\mathrm{L}$, et al. Practical uses of end-
tidal carbon dioxide monitoring in the emergency departtidal carbon dioxide monitoring in the

10 Robinson SM, Harrison BDW, Lambert MA. Effect of a pre-printed form on the management of acute asthma in an pre-printed form on the management of acute asthma in an accident and

11 Quine MA, Bell GD, McCloy RF et al. Prospective audit of upper gastrointestinal endoscopy in two regions of comments]. Gut 1995;36:462-7.

12 Jackson R, Feder G. Guidelines for clinical guidelines. BMf 1998;317:427-8.

13 Thomson v James and others (1996). 31 BMLR 1. Medical Law Monitor 1997;April:7-9.
7 Association of Anaesthetists of Great Britain and Ireland. sia and recovery. London: Associati England: safety, staffing and sedation methods [see 